\title{
Translation and Linguistic Bridge-Building : A Study of Dr. Bhupen hazarika's Songs in Translation
}

\section{Deepanjali Baruah}

\begin{abstract}
Translation at present has been recognised as an independent discipline. Translation is not only confined to literary texts but it has also shifted its range to the interpretations of different cultures. The iconic figure of the musical world of Assam, Dr. Bhupen Hazarika has con $\neg$ tributed towards social mobility and change through his immortal creations of songs which have been translated into other Indian languages as well. The Bengali translations of some of his most significant songs provide ample opportunities of research in this area.
\end{abstract}

In this paper an attempt will be made to analyze a few Bengali versions of Dr. Hazarika's songs from the point of :

* Capacity to change social attitudes.

* Historical events connected with the translated songs.

* Nation and linguistic bridge-building.

* Loss and gain in the translation process

Keywords: Translation, Bhupen Hazarika, songs, interpretation, attitude

A. J. Thomas has opined, “...translation is seen as acultural activity involving cultural codes". ${ }^{1}$ Translation serves as an important tool for social change and mobility. The strategies adopted for translation help in recording events in history and underlining the relations between nations, cultures, languages and communities which can exist. In a country like India, translation of literary/ 
cultural texts helps to communicate thoughts and feelings between people belonging to different regions. Translation works that have taken place in both inter-lingual and intra-lingual areas in India have fostered the spirit of cooperation, coexistence and coordination, eliminating isolation and confrontation.

\section{Capacity to change social attitudes :}

Dr. Bhupen Hazarika, in short Bhupen da may be basically ascribed as a social reformer, a humanist and a harbinger of love/ passion and universalism. His songs bear everything that he feels, sees, imagines and hopes. We see in his songs the complexities of life, the tension between existence and essence, life and death, soul and body. Through his songs he tries to engage himself with the polarities of life seemingly unwilling to succumb to the pressures of life and so he sang : Sangram jodi jibomm eti naam / (set) sangram houk tor priyo. ( If struggle is the other name for life (that) struggle is dear to me) Dr. Hazarika has mainly focused on ordinary man's ordinary conflicts.

Dr. Bhupen Hazarika's songs have not only been translated into Bengali and Hindi but a number of other languages as well. This has obviously transformed translation into an intercultural activity. According to Lambert and Robyns, translation has now been redefined as out migrations - through - transformation of discursive elements (signs)" and as the "process during which they are interpreted (re-contextualized ) according to different codes."2

The translation of Dr. Hazarika's songs into so many different languages has erased the boundary between the source and the target texts. When we take into account the Bengali translations of Hazarika's songs we see that they frequently achieve linguistic equivalence or in other words become 'word for word' translation. The translators and Dr. Hazarika himself (Dr. Hazarika also translated some of his songs into Bengali) have tried to maintain homogeneity on the linguistic level of both the languages and so the Bengali versions have become as popular as the Assamese originals. 
At the time of India's Independence, the traditional Assamese was full of orthodoxy and prejudices. People at the lower end of the socio-economic ladder mostly bore the brunt of class and caste prejudices. Dr. Hazarika has tried to challenge this attitude of the Assamese people by writing lyrics on the marginalized like the fisherman, the stone cutter, the train driver and the poor villagers.

His dola, he dola, (palanquin, o palanquin) speaks of the tiresome and tedious lives of the palanquin carriers. He sings of the sweat and toil of these people while bearing the weight of the rajas and maharajas in the palanquins from ages to ages.

He sings, " Morhe loratik eibar bihute / nidilo sutare sola / Sokulu olaleu manti nabhango / Korhiyai loijao dola. (I could not give a shirt to my son during the Bihu / even though tears flow I shall not break down and continue to carry the palanquin).

The Bengali translation by Shibdas Bandopadhyay goes on in a slightly different way : ct Hai hai mor cheletir ulongo shorire / ektio jama nei-khola / Du chokhe jol ele montoke bedheje / tobu boyejai dola." (Alas ! on my son's naked body there is not even an open shirt / when tears well up in my eyes I try to check them / still the palanquin moves on). Here the most noticeable thing is the interplay of the words in both Assamese and Bengali versions. The palanquin carrier in the Assamese song is the subaltern and the rajas and maharajas are the feudal oppressors. The palanquin carrier has the strength of mind though he is unable to give a shirt to his son during "Bihu". On the other hand the Bengali translation becomes more poignant in those lines when the translator adds another dimension by slightly amending the original to suggest not a child deprived of a festive gift but another child at the bottom of the socioeconomic ladder lacking even the barest essential to cover his body.

Dr. Bhupen Hazarika himself experienced the exploitation of the colonial British in India and their strong opposition to socialism. He also experienced the aftermath of India's independence 
; the powerful influence of the jaminders / the planter class and the absence of equality and justice. In an interview he once said, "I have always considered my music/songs as a weapon for social change. Real songs are those which portray justice in magnified form......" "Now there is need to do something so that old moral value of the society may come back."3

The ideas built on the interest of change of social attitudes can be felt in songs like - soru soru somajar soru soru bicharat bhekuliye bor laj pai. (Even frogs are ashamed of the narrow viewpoints of small society). jiyai thaki ekhon samaj garhibor mor mon ase. (I want to live to create a society). Autorikshaw solao ami duyu bhai (We two brothers drive autorikshaw)

One of the most beautiful songs written by Dr. Bhupen Hazarika is the "ode" on the river Brahmaputra. This is a song that questions the river for its indifference as it flows, oblivious to the sufferings of the people who live by its banks. Dr. Hazarika met the legendary black singer Paul Robeson in America who sang $\mathrm{Ol}$ ' man river, a beautiful anthem for black liberty. He was influenced by the rhythm of the song which bears a vivid picture of the eternal unchanging Mississippi. So the outcome of this is the song burha luit boan kio? (why do you flow old Lohit ?). The Bengali translation of this song has been made by Sri Shibdas Bondopadhyay as Ganga boicho keno ?. In the Bengali translation Bandopadhyay has used the words Mantra diye I lakhya janer instead of Assamese unmadanar abhigyatare. The use of the words mantra diye / lakhya janer has given to the song an element of mysticism and elegance. 'Ganga' like 'Brahmaputra" or 'Lohit' is a large river having perhaps even a greater religious/cultural significance in the Pan Indian context. By substituting the national for the regional the translator has given the song a national resonance. When the song is sung (both Assamese and Bengali versions) the masses participate with the content and song so this song has undoubtedly turned out to be a mass song ".

Andre Lefevere has opined about literal translation that here emphasis is put on word for word translation which distorts 
the sense and the syntax of the original. We have seen that the translation of Dr. Hazarika's songs have been basically literal but the beauty and the syntax of the original have not been distorted, rather the translated versions are equally popular like the originals. The translator has infused accessible and aesthetically satisfying Bengali style into Bhupen Hazarika's songs.

\section{Historical events connected with the translated songs :}

Dr. Bhupen Hazarika has been a living witness of some of the historic events in North-East India after the Partition in 1947. Some of the popular songs are the reflections of these events. The first was the Language Agitation of 1961-62 and the second was the Assam Movement of 1977-84. After the Independence of India, the people of Assam had great expectations from the first Congress Ministry in Assam. Unfortunately those expectations were not fulfilled and by the summer of 1978, several movements started in the state championing a variety of causes. This period could be marked as a period of unemployment, social unrest and economic backwardness for Assam. The year 1979 was also a year of strikes and agitation by the students and teachers of schools and colleges. "On $9^{\text {th }}$ November, 1979, the AASU - AGSP announced a drive out foreign nationals campaign, with a state-wide general strike to follow. There were clashes in Naharkatiya between Bengalis and Assamese throughout $8^{\text {th }}, 9^{\text {th }}$ and $10^{\text {th }}$ November."

It can be argued that the events had a left a deep mark in the mind of Dr. Bhupen Hazarika as a result of which he created some immortal songs on themes like humanism / compassion youthful vigour, Assamese / Bengali unity etc. In 1979 the police atrocities on the people of Assam created several casualties and this led Dr. Hazarika to write: Naba naba purushor nopowar prokashok / bhorire moharibo nawari (The outburst of deprivation among the new generation cannot be erased under foot).

Again the song rim jim rimjim borosune / nupur bojai 
kot? ei Asom desot, ei Asom desot. (Where does the chiming rain drops create the music of anklet ? In my land Assam) was written in 1956 but during the Assam movement in 1979 Dr. Hazarika gave it a new shape. In the translated version of this song by Shibdas Bandopadhyay the substance of the original song is retained but the form is changed : rimjhim rimjhim boroshar oi nupur bajai ke / Amar deshete, ei Amar deshete (In my own land). The song has been allowed to transcend the regional register and achieve a resonance in a wider psycho-social context. In the original song the music of rain could be heard only in Assam whereas in the Bengali version the same music could be heard in India. Here Bandopadhyay stresses on national integration and at the same time the unity and brotherhood between the Bengalis and the Assamese when he recreates the song thus "Bhaike Kothai Joriye dhore bhaiyer bukete / Obohela soriye rakhe hansi mukhete. / O' Amar matir deshete." ( Where is a brother always clasped in an embrace in his brother's chest / where is neglect kept afar by smiling faces. In the land of my soil).

The language agitation created disturbance in places like Cachar, Karimganj, Dhubri and Goalpara. When the State Government tried to impose Assamese as state language, the people living in these places (where Bengali dominance could be felt) voiced against this implementation. As a result there was friction between the Assamese and Bengalis leading to lot of violence and deaths. Dr. Hazarika, the composer and poet has been a voice of moderation. He appreciated the fundamental points raised by the AASU but at the same time he also felt that work must proceed in the process of a syntheses. Regarding the Language Agitation he remarked that Assamese as a link language is a necessity but no language must be thrust upon any other group. Dr. Hazarika has recorded dozens of his own compositions in Assamese as well as other languages. One of such albums is Aami ekjajabar recorded by the HMV in the crucial year of 1980. This cassette consists of fifteen Bengali songs sung by Dr. Bhupen Hazarika which speak of Assamese-Bengali unity. Dr. Bhupen Hazarika's perturbed mind wanted to break the walls of differences between the Bengalis and Assamese. Through these songs he tried to reach the people regardless of language barriers 
and make them feel that they are all brothers. This is also expressed in one of the songs, Aajjiban khuje pai chute chute aai. This song is a translation from the Assamese original Ajijiban butolibi hanhi hanhi aah. In this song we observe the speaker's concern with basic moral values and a journey towards the attainment of freedom. The speaker here states his passionate longing for Assamese-Bengali unity and re-interprets his nation's cultural heritage. He requests the people to come out of their narrowness, confrontations and mingle with one another. Another song translated into Bengali - Pratiddhani shuni ami pratiddhani shuni by Shibdas Bandopadhyay is an adaptation from the Assamese Pratiddhani sunu moi pratiddhani sunu (I hear echoes) possesses certain lines like - Manab shagarer kolahol shuni (I hear the voice of human seas). This song expresses the latent power of ordinary people who work for a common cause. If people come out together and shout in unison they can shatter mountains. The theme of the song is as old as the 'Panchatantra'. It has however been rephrased and given a new context to usher in communal harmony.

\section{Nation Building / Linguistic Bridge-Building :}

"Translation plays an essential role in determining how a nation establishes its identity, in terms of others, be this through opposition to foreign influences, through assimilation or 'naturalization' of the foreign whereby differences are erased to a great degree possible, or through imitation of another, usually dominant culture." 5 This view of Paul St. Pierre definitely establishes the fact that translation helps in its effort at nation building and at the same time linguistic bridge-building. Dr. Bhupen Hazarika's translation of songs into various languages has brought about national integration particularly in a multi-lingual nation like India. The translations have oriented towards the explicit end of reforming power-structures and relations present amongst numerous races, communities and religions. An immensely popular Bengali song by Shibdas Bandopadhyay sung by Dr. Hazarika - Ganga Amar Ma / Padda Amar Ma (Ganga my mother / Padma my mother) has been translated into Assamese by Dr. Hazarika as Ganga mor Ma / Padma 
mor Ma. This song has been an attempt to rediscover the affinity and brotherhood between the Assamese and the Bengalis. Dr. Hazarika was influenced by Nazrul Islam's revolutionary creations. When he sang Ganga Amar Ma in his rasping baritone in Bangladesh people were overwhelmed with emotion. This song clearly manifests the mutual exchange and partnership in shared values of a composite, multifarious culture.

Paul Robeson's song We are in the same boat brother /you tip one end and it rocks the other has been translated into Bengali by Shibdas Bandopadhyay as Morajatriekai toronir / Sohojatri ekai toronir. The Assamese translation of this song by Dr. Hazarika goes like this Ami ekekhon nawore jatri / Sohojatri ekekhon naware. The recreation of the song in Assamese and Bengali stresses on the unified force of humanity. The song is a faithful reflection of life which shows the ways to human beings to fight with strength against all odds.

The translation of a worldwide popular song like this indicates enormous effort on the part of the translator. The translation of Bandopadhyay into Bengali and Dr. Hazarika's translation into Assamese show brilliant insight and creativity and consequently both the works have turned out to be arts rather than crafts. In India translation is a major literary activity which is perhaps because language is one of the greatest wealths of India and translation enables us to speak or write or read to each other. No two languages are same. They differ in form and structure and translation acts as a kind of linguistic bridge-building between two languages and cultures.

Dr. Hazarika wrote most of his songs during his stay in Calcutta. One of the songs he wrote there is - Moi etijajabor / dhamr dihinge dipange lauru nibisari nija ghar. (I am a wanderer / running here and there across the globe without hankering for a home). Shibdas Bandopadhyay has translated the song thus - Ami ekjajabor / Prithivi amake apon koreche / bhidechi nijer ghar. (I am a wanderer / the earth has welcomed me making me forget my own home). This is 
a wonderful Bengali translation. Here the translator has chosen words appropriately to produce the right tone. The original Assamese song is content merely to describe the rootlessness of a habitual nomad. On the other hand the translator goes one step farther and provides motivation for the speaker's wanderlust. The world has welcomed him with open arms robbing him of the desire to settle down. In the original song the desire for global citizenship is not very clear but in the translated version the vision has transcended the barriers of local and regional and has reached the national and global. The whole song thereby becomes philosophical leaving immense scope for nation and linguistic bridge-building. Other notable songs like Manuhe Manuhar babe (Human for human) translated as Manush manusher jonye, (By S. Bandopadhyay). Sagar Sangamat Kotona Saturilo (In the confluence of ocean I have swam a lot) translated into Bangali as Sagar Sangamer Shatar Keteshi Koto ; Mor Geetor hejar shrota! Tomak Namaskar. (The thousands of listeners of my song! I salute you.), translated into Bengali as Amar ganer hajar shrota! tomake namaskar. Apart from these translations there are a lot more translated versions in Bengali. The translations have been done so beautifully that sometimes it is difficult to point out the original. When translation achieves this criterion then it can be rightly called perfect translation.

Bijoy Kr. Das opines, " Translator not being the original author (for the work in hand is never his own) takes into himself the task of bridge-building between the mind of the another and the mind of the reader or between the SL text and the TL text."6 In the Bengali translations of Dr. Hazarika's songs a bridge has been established in the linguistic, stylistic and pragmatic levels. The translator has understood that he has to prove himself as the mediator between two different cultures and languages. Dr. Hazarika's roots might cleave firmly to Assam, but he learnt to identify with the rest of India alter moving to Calcutta. Dr. Hazarika himself opined,kt The roots may be entrenched in the soil but the plants can interwine." ${ }^{17}$ The Bengali translations of Dr. Hazarika's songs have been like plants that interwine thus unifying two cultures and a nation. 


\section{Loss and gain in the translation process :}

Translation in the first place is a transference of meaning from the source language to the target language. Sometimes in translation it is difficult to find the exact words for the original. Therefore the question of loss and gain arises in the process of translation. To avoid the Toss' in translation a translator may keep in mind the following points :

- Firstly, the translator should have command over both the languages.

- Secondly, he/she should try to provide the lexical equivalent in the target language to the original text.

- Thirdly he/she should keep in mind the socio-cultural factors governing both source and the target languages.

If these criteria are followed then in the translation process less will be lost and more will be gained.

A very popular song of Dr. Hazarika, Sirojugamia dhou tuli; dhou tuli / sir natun pansoi uti jai. (Ever new boats sail raising eternal waves). This song has been translated into Bengali by Dr. Hazarika himself as Sirojiboner dheu tule dheu tule / Siro natun dingiti bheshejai. It is a song that celebrates the vibrant potential of life in its ever changing creative quality. In this song the word sirajugamia (eternal) has been replaced as sirajibaner (life long). The word eternal has a deeper meaning than the word life long. Sirajugamia (eternal) expresses the quality of endurance whereas sirajibaner (life long) relates to the span of a single life time. The use of the Assamese word sirajugamiya has enriched the original song whereas the use of the word sirajibaner in the Bengali version seems to have lessened the intensity of the original word.

Another prominent song Akashi Ganga bisora nai / nai bisora swarna olonkar (I am not searching for the celestial Ganges /1 am not searching for gold jewelry either) has been translated into 
Bengali by Shibdas Bandopadhyay. This song voices the deep hidden personal longings of even the socially committed artiste. Dr. Hazarika in the same song sings : Maha maha, nat ghare ghare / kantha sonit nigoralu. (I have set my voice bleeding). The struggle and pain of a creative artiste has been successfully echoed in the phrase Kantha sanit nigaralu (I have let my bleeding voice flow ). On the other hand this powerful amalgamation of words in the Assamese original seems to have been lost in the Bengali translation : Sena sena shrotajanatar hansite khushite bharechipran. ( My heart is thrilled with the cheer and joy of familiar audiences ). Here the pain and struggle in the life of the artiste has been left out but the sense that the artist lives for the people and derives happiness when the people are happy gives a new turn to the song. The translator has retained the 'sense' of the song as much he can. But along with the 'sense' semantic compatibility is also equally important. Translation has its advantages and limitations which need to be weighed carefully.

The translator is a reader, an interpreter and a creator. The Bengali translations of Bhupen Hazarika's songs reveal the fact that a translator may not necessarily remain bound to the original and these renderings may be considered as 'new writing' rather than imitations. A translated text like the original frequently contributes to the transformation of social attitudes. In the hands of an excellent translator like Shibdas Bandopadhyay, Dr. Bhupen Hazarika's songs have gained added depth and significance, serving to foster new strains of communal accord at a volatile juncture in the history of North-East India. Dr. Hazarika's lyrics promised change, "I remember writing - " I am a spark and I have come to build a new India and a new Assam." ${ }^{8}$ The translated versions of a few songs mentioned in this paper capture the essence of the North-East and Bengal in their imageries and sounds. 


\section{NOTES}

1. Das, Bijoy Kumar. 2005. A Handbook of Translation Studies. Chap. 7: Translation as Nation Building. Atlantic, New Delhi. Page 79.

2. ibid. P. 75 .

3. Das, Bijoy Kumar. 2005. A Handbook of Translation Studies. Chap. 12: Comparative Literature and Translation Studies: A Correlation. New Delhi, Atlantic. P. 131.

4. Dr. Bhupen Hazarika Rachanavali. 2008. Vol. 3. Surya Hazarika Saikshik Nyas, Guwahati. P.P. 1936, 1937

5. Dr. Bhupen Hazarika Rachanavali. 2008. Vol. 3. Surya Hazarika Saikshik Nyas, Guwahati. P. 1943

6. Kalita, Pulin; Jalan, Gopal and Parashar, Anubhav. 2007. (ed). Biswanagarik Bhupen Hazarika. Bhatia Samita. Old Man River. Chandra Prakash, Guwahati. P. 175.

7. Murty, T. S. 1983. Assam the Difficult Years. Himalayan Books. New Delhi. P. 19.

8. Thomas, A.J. 2006. Review of In Translation, References, Transformations ed. By Paul St-Pierre and Prafulla C. Kar. Sahitya Akademi's Bi-Monthly Journal. Vol L No. 3. May-June 2006 edNirmal Kanti Bhattacharjee, New Delhi. Sahitya Akademi. P. 196.

\section{REFERENCES}

Dutta, Dilip Kumar. 1982. Bhupen Hazarikar Geet Aru Jibon Rath. Sribhumi Publishing Company, Mahatma Gandhi Road, Calcutta.

Lahiri, Topoti. 1991. Bhupen Hazarikar Sangeet O Jibon Chakra. Swapna Printing Works Pvt. Ltd., Calcutta. 